\title{
Vicente Mojica y la vigilia de la poesía. Contra la consumación de un olvido historiográfico
}

\author{
Vicente Mojica and the vigil of poetry. Against a \\ historiographical forget
}

\section{Vicente Mojica e la vigilia de la poesía. contra la consumación de un olvido historiográfico}

\author{
Manuel Valero Gómez \\ Profesor asociado. Universidad de Valencia. \\ Cómo citar este artículo en edición digital: Valero, M. (2018). Vicente Mojica y la vigilia de la poesía. Contra la consumación de \\ un olvido historiográfico. Cultura de los Cuidados (Edición digital), 22(50). \\ Recuperado de http://dx.doi.org/10.14198/cuid.2018.50.07 \\ Correspondencia: Remitirse al correo electrónico. \\ Correo electrónico: Manuel.Valero@uv.es \\ Recibido: 28/06/2017; Aceptado: 18/10/2017
}

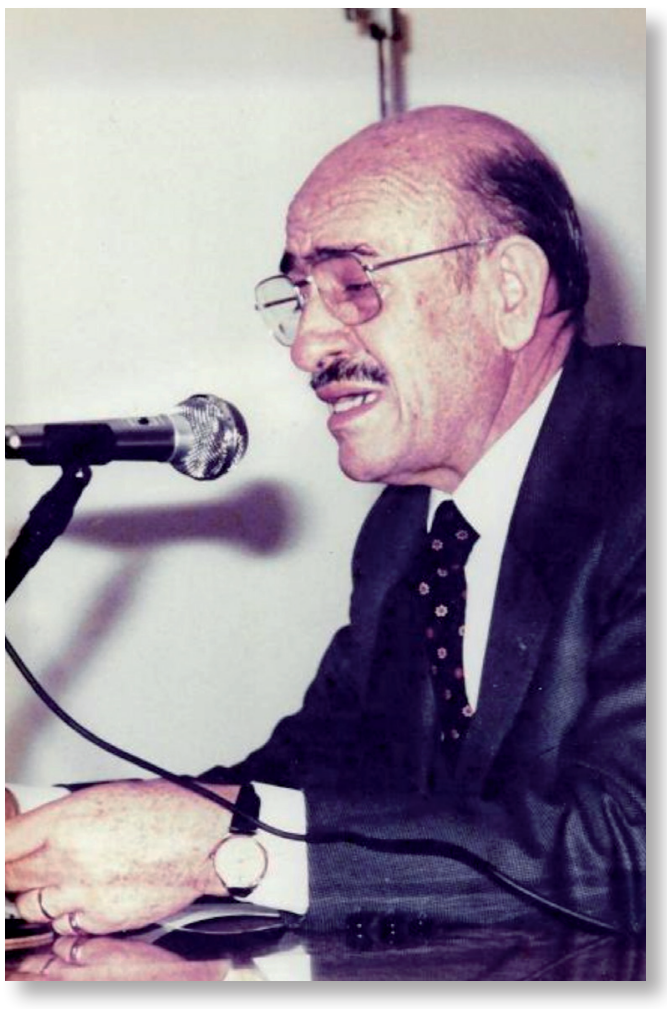

ABSTRACT

Vicente Mojica was born in 1923 and died in 1989 . He is one of the most important poets in Alicante. Mojica published near thirty tittles about poetry, theatre, narrative or essay.
In the next lines, we are going to speak about Mojica's poetry. He met with intellectuals of the first years of the Spanish post-war period. We can name some books of Vicente Mojica, for example, Espejo de la consumación, Al pie de la esperanza o Libro de las tribulaciones.

Keywords: poetry, Alicante, Post-war period, mystic, nursing.

\section{RESUMEN}

Vicente Mojica nace en 1923 y muere en 1989. Mojica es uno de los poetas más importantes de Alicante. Entre su bibliografía puede encontrarse cerca de treinta títulos de diversos géneros: poesía, teatro, narrativa o ensayo. A lo largo de las próximas líneas, analizaremos la trayectoria poética de Mojica. Como es sabido, trabó contacto con el grupo de intelectuales alicantinos de posguerra. Algunos de sus libros más importantes son Espejo de la consumación, Al pie de la esperanza o Libro de las tribulaciones.

Palabras clave: poesía, Alicante, posguerra, mística, enfermería. 


\section{RESUMO}

Vicente Mojica nace en 1923 y muere en 1989. Mojica é um dos poetas mais importantes de Alicante. Entre sua bibliografia pode encontrar onde se encontram os títulos de géneros: poesía, teatro, narrativa o ensayo. A lo largo de las línea líneas, analiza la trayectoria poética de mojica. Como é sabido, trabou contacto com o grupo de intelectuais alicantinos de posguerra. Algunos de sus libros mais importantes filho Espejo da consumação, Torta da esperança o Livro das tribulações.

Palavras-chave: poesia, Alicante, pós-guerra, mística, enfermagem.

\section{INTRODUCCIÓN:}

Pocas dudas existen de que Vicente Mojica (1923-1989) es una de las voces más importantes de la poesía valenciana de posguerra. Nacido en Alicante, desarrolla toda su trayectoria literaria en esta ciudad y publica cerca de una treintena de títulos. Los géneros que Mojica Benito cultiva son diversos: la narrativa, el teatro ${ }^{1}$, la crítica o la literatura infantil ${ }^{2}$ son buenas muestras de ello. El poeta alicantino crece en una familia humilde a la que le toca sufrir una de las coyunturas más duras de la historia de España. Empieza a trabajar en el Club de Regatas, con apenas diez años, y para el Socorro Rojo Internacional durante la guerra. Tras formar parte de la farmacia de don Vicente Otero como mancebo, consigue el título de Practicante en Medicina y Cirugía en la Universidad de Valencia (1943), gana por oposición una plaza de practicante en el Hospital Provincial $(1950)^{3}$ y se casa con Josefina Marhuenda en 1951.

Durante los años cuarenta inicia su andadura poética, ya que participa en certámenes, emisoras de radio, prensa e incluso forma parte del ambiente fogueril. Este primer periodo está compuesto por su educación religiosa y formación profesional. Sin embargo, no es hasta la década siguiente cuando Vicente Mojica se incorpora al ambiente cultural de Alicante y más concretamente al conocido grupo de la primera posguerra alicantina ${ }^{4}$. Pese a que la coyuntura histórica que sigue a la guerra está marcada por el hacinamiento ideológico y la represión más severa ${ }^{5}$, conocemos la existencia de tertulias a las que acuden autores de merecido prestigio local (Bautista, 1988, 30).

\footnotetext{
${ }^{1}$ Según tenemos constancia, la producción teatral de Mojica se reduce al auto sacramental en verso El sembrador de vientos, publicado en el año 1985 gracias a la Caja de Ahorros Provincial de Alicante. Para esta cuestión, proponemos la lectura de Fernández (2008).

${ }^{2}$ Como veremos a lo largo de este trabajo, la presencia de los hijos y los nietos es un factor importantísimo en su producción poética. Tal es así que Vicente Mojica publica dos poemarios infantiles: Cancionero infantil (Gráficas Díaz, Alicante, 1983) y En tu voz de agua clara (Sinhaya, Alicante, 1986).

${ }^{3}$ Pascual Ruiz Galiano (2008), amigo cercano y compañero de oposiciones, cuenta al detalle cómo prepararon sus candidaturas al Cuerpo de A. P. D. (Asistencia Pública Domiciliaria) en junio de 1948.

${ }^{4}$ Vicente Ramos $(1990,16)$ pone fecha al primer encuentro entre Vicente Mojica y los jóvenes que forman parte de la intelectualidad literaria de posguerra en Alicante. El historiador señala la celebración del cuarto Mensaje Literario, revista oral que tenía lugar cada quince días en el insigne Bar Club, durante el día 7 de abril de 1951 y con la presencia de Juan Guerrero Zamora, Mariano Báguena, Carlos de Santiago, Reinaldo Asensio, Adrián Carrillo y Carmen García Bellver.

${ }^{5}$ Pese a que algunos historiadores se empeñen en señalar una supuesta "conjura" que se vivió en muchas ciudades -como Alicante- para salir de un, también supuesto, "letargo" posterior a la Guerra Civil (Ramos, 1992-1994, I, 133), los primeros años de la posguerra española fueron igual de crudos o peores que la propia guerra (Alonso y Sánchez, 1992; Cerdán Tato, 1978, 120-121). Por ejemplo, Miguel Ors Montenegro (2008) señala una "visión de la guerra y, por extensión, del franquismo, que coincide en líneas generales con el revisionismo histórico" (16), al mismo tiempo que enumera los métodos de la represión franquista durante la posguerra ilicitana (163-164).
} 
Por ejemplo, el Café Central de Alicante es un nexo de reunión durante esta década; o el Bar Club, que monopoliza los encuentros de esta cofradía de intelectuales a los que se suman (entre muchos otros) Manuel Molina, Rafael Azuar, Vicente Ramos o Francisco García Sempere (32-33).

Por un lado, se puede hablar de un elenco de excelentes poetas que dan impulso a algunas de las mejores revistas literarias del panorama nacional -cítense los casos de Arte Joven (1940), Intimidad poética (1943-1944), Música y Arte (1944), Sigüenza (1945), Cuadernos Literarios (1945), Verbo (1946-1963) o Estilo (1947)-, así como colecciones poéticas (Leila, Silbo o Ifach). Mientras que, por otro lado, una serie de narradores -José Bauzá, Alejandro Bonmatí, Pascual Bosque, Enrique Cerdán Tato, Ernesto Contreras, Gonzalo Fortea, Francisco García Sarría, Manuel Girón y Eduardo Trives (AA. VV., 1975)- se aglutinan en torno a lo que ha sido denominado

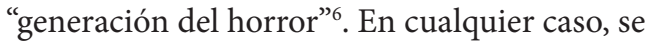
inicia una ebullición cultural en el panorama literario de la Alicante de posguerra que llega a tomar contacto, entre otros, con Camilo José Cela, Blas de Otero, Gabriel Celaya o Vicente Aleixandre (Cerdán Tato, 1992, 9-14; Bautista, 1988, 45-48; Molina, 1973). Aunque por mucho que algunos se empeñen en aseverar un ambiente de "cordialidad general" (Ramos, 1999), las disputas literarias y los rigores del franquismo estuvieron presentes (López Gorgé, 1989).

Por su parte, Vicente Mojica se abre paso en mitad de este contexto y gracias al citado núcleo poético ve la luz su primer poemario, Llamada al corazón, en el año 1958 y en la editorial Silbo. A partir de aquí, el escritor alicantino desarrolla una rica producción poética que culmina con la publicación de Obra poética $1958-1988^{7}$, justo en 1989 , año de su muerte. Entre sus libros de poemas más destacados podemos citar Geografía del llanto ${ }^{8}$, La paz nos esperaba ${ }^{9}$ Árbol de mi sombra ${ }^{10}$ y Espejo de la consumación $^{11}$, quizá su poemario más elaborado. Al mismo tiempo que amplía su nómina lírica, el autor posee un papel importante en el Instituto de Estudios Alicantinos, es Cronista oficial de la Junta Central de la Fiesta de Moros y Cristianos de Alicante, Vicepresidente de Cultura y Coordinación del Ateneo Científico, Literario y Artístico de Alicante y dirige las colecciones editoriales Sinhaya y Alcodre.

\section{DEMARCACIÓN ÉTICA ESTÉTICA E IN- FLUENCIAS}

En líneas generales, la recepción crítica de la poesía de Vicente Mojica ha sido escasa, aunque ha corrido mejor suerte que sus compañe-

\footnotetext{
${ }^{6}$ José Bauza (1975), uno de los integrantes de esta joven promoción de narradores alicantinos, cuenta de primera mano cómo se gesta el grupo. Dicha "generación", a la que Cerdán Tato se incorpora de forma tardía, nace en el verano de 1950 gracias a unos jóvenes en vacaciones que se reúnen en el american bar del Hotel Samper (Cerdán Tato, 1992, 10). Para más detalles sobre este tema remitimos al citado texto de Bauzá (1975) - “Noticia sobre la generación del horror"- que aparece a modo de prólogo en la antología Narradores alicantinos de 1954 (AA. VV., 1975). Por otro lado, y para una visión completa de los años cincuenta en Alicante, proponemos la lectura del número 14/15 de la revista Canelobre (1989).

${ }^{7}$ Vicente Mojica Benito, Obra poética 1958-1988, Alicante, Caja de Ahorros del Mediterráneo, 1990.

${ }^{8}$ Vicente Mojica Benito, Geografía del llanto, Alicante, Silbo, 1963.

${ }_{9}^{9}$ Vicente Mojica Benito, La paz nos esperaba, Alicante, Caja de Ahorros del Sureste de España, 1966.

${ }^{10}$ Vicente Mojica Benito, Árbol de mi sombra, Málaga El Guadalhorce, 1976.

${ }^{11}$ Vicente Mojica Benito, Espejo de la consumación, Valencia, Anteo, 1987.
} 
ros de generación. Siendo sinceros, el recuerdo que ha llegado hasta nosotros pertenece a las semblanzas del ambiente cultural de la época, así como a los rompecabezas que constituyen la historiografía artística de provincias ${ }^{12}$. De hecho, y la siguiente afirmación pertenece ya a la categoría más propia de la opinión o del vaticinio, quedan pocos años para que la figura de Vicente Mojica sufra un severo golpe, puesto que la quinta de alicantinos que comparten generación está llamada a desaparecer y es este colectivo y no otro quien guarda un mayor respeto y recuerdo hacia el poeta. A la hora de perfilar una bibliografía crítica sobre el autor es necesario consultar los pertinentes prólogos y los índices de información dispersa, aunque adyacentes a la cuestión que nos ocupa. En este sentido, el homenaje que la revista AUCA de las Letras realizó a Mojica en su número 14 (noviembre de 2008) es una de las herramientas más útiles. También puede mencionarse el destacado lugar que ocupa Vicente Mojica en las siguientes antologías de ámbito local: Estudios de Literatura Alicantina de Vicente Ramos (1979, 299-326), Antología de la Poesía alicantina actual (1940-1972) de Manuel Molina (1973) y el reciente Tres poetas alicantinos de Luis Español Bouché (2012).

Aunque a primera vista parece positiva la idea de que la obra de Mojica disfrute de un cierto colchón crítico, los vericuetos y las trampas de la historiografía literaria tradicional pueden hacernos pensar lo contrario. Por ejemplo, Vicente Ramos (1990, 18-19) -uno de los grandes valedores de Mojica y a su vez cacique de la cultura provincial durante buena parte de la posguerra- señala en el prólogo a la Obra poética 1958-1988 que "la poesía de Vicente Mojica no contiene ni aderezos moder-

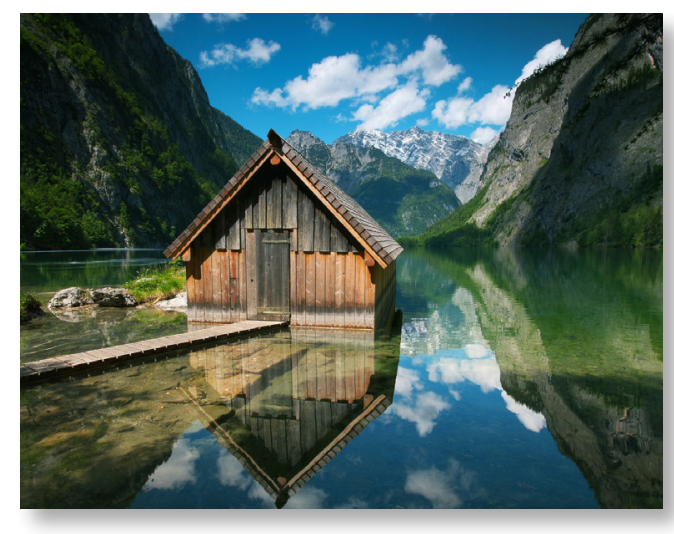

nistas ni rigores intelectuales (...) nada, pues, de esteticismos, ni eticismos ni sociologismos; mucho menos de politicismo de cualquier especie". Es decir, afirmaciones de tal reduccionismo no solo invitan a sesgar el verdadero valor poético de cualquier producción poética, sino que favorecen la consumación de su olvido, cuando no la tipificación de un estereotipo. El estudio de su obra precisa mayores complejidades que en el ejemplo citado no se abordan, conste en cualquier caso que el propio Ramos lleva a cabo análisis más lúcidos sobre el poeta.

Sea como fuere reivindicamos una lectura en defensa propia (García, 2012) que no solo nos ampare "del mundo hostil en que vivimos y del lugar que nos ha tocado en él", sino que también nos proteja del entramado positivista que se ha levantado en torno al estudio del objeto que hoy conocemos como Literatura. Dicho lo cual, y en relación a Mojica, limitar su producción poética al eje "amor humano-amor divino”, como así hace el crítico mencionado, pasa por alto elementos imprescindibles a la hora de enjuiciar la magnitud del poeta. Por tanto, nos gustaría matizar que Vicente Mojica es un poeta religioso en tanto en cuanto es un poeta católico y sus temas predilectos (la vida familiar, la preocupación por el hombre o la

\footnotetext{
${ }^{12}$ Para más detalles sobre esta cuestión proponemos Valero Gómez (2015).
} 


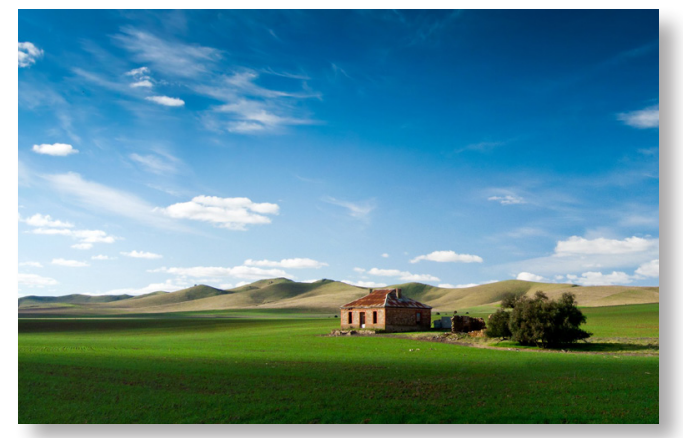

miseria) "participan de una visión católica en su primigenio sentido de universal, de la existencia" (Español, 2012, 15). En todo caso, Mojica plantea en sus poemas una "trascendencia" (Alonso Ruiz, 2015) en la que la moral cristiana le ayuda a "entender y restaurar al mismo objeto invocado (Dios)" (Gracia, 1980, 163) y hace patente una forma personal de abordarlo (Español, 2012, 12).

No se trata tanto de que su poesía sea un "trámite" o un "automatismo" en su "exhortación" a Dios (Gracia, 1980, 162), sino que gracias a un intimismo de corte "esencialmente amoroso" (Ramos, 1979, 303) hace suya una misión profética en la que "pide a Dios que le otorgue el don de hablar de la creación a sus compañeros de vida" (Gracia, 1980, 165). Según considera un poeta como Francisco Alonso Ruiz (2015), que ha tenido la suerte de compartir junto a él amistad y poesía, la producción literaria de Mojica Benito es una "mezcla entre el barroco y el modernismo" debido al empleo de formas clásicas (por ejemplo, el soneto) y a una construcción rimada muy elaborada. Hablar de su poesía nos remite directamente a la encrucijada que vive el panorama lírico español durante los años cuarenta y cincuenta: el impulso neoclasicista y religioso que predomina en las revistas Escorial y Garcilaso, la apertura neorromántica gracias al realismo íntimo trascendente de Luis Rosales, Leopoldo Panero y Luis Felipe Vivanco, más la preocupación obsesiva por la existencia del ser humano.

También pueden destacarse otras influencias notorias. Una de ellas, por citar un ejemplo evidente, son los autores clásicos de nuestra literatura, como Quevedo o Lope de Vega. Pero pasemos ahora a otros casos que aportan un terreno más jugoso a la hora de argumentar las características de su poética y que nos conectan con nuestra poesía más reciente. Miguel Hernández es un nombre ineludible porque Mojica forma parte de ese círculo -junto a Molina y Ramos, principalmente- que lucha por mantener viva la memoria $y$, fundamentalmente, el magisterio del autor oriolano. En su reciente estudio, Luis Español (2012, 23-25) dedica un epígrafe bastante completo a la relación entre Mojica y Hernández. Por ejemplo, entre los detalles más reseñables, merece la pena decir que compartieron la editorial impulsada por el Socorro Rojo o las evidentes referencias que se pueden encontrar en Llamada al corazón (1958), su primer libro.

Desde luego, hay un rastro hernandiano en la producción poética de Mojica que se deja sentir gracias al léxico y la construcción del soneto. Sin embargo, la relación va más allá de una mera influencia o presencia estilística. No será muy arriesgado afirmar que Mojica vio en Hernández un modelo ético estético. $\mathrm{O}$ mejor dicho, Mojica vio en buena parte de la poesía hernandiana un modelo ético estético. Y dicho matiz no es casual si atendemos a un documento muy relevante a la hora de establecer el diálogo que tenemos entre manos. Vicente Mojica publica en el número (73-75) que la revista Litoral dedica a la "Vida y muerte de Miguel Hernández" (1978) un interesante artículo titulado "La religiosidad de Miguel Hernández y su poesía” (pp. 105-122). Por un lado, el poeta alicantino muestra cierta valentía cuando refle- 
ja que la religiosidad es "una de las partes más discutidas y controvertidas" de la "imagen incompleta" (105) que hasta ese momento se había mostrado del autor oriolano. Por otro lado, relaciona la religiosidad hernadiana (106) con su lugar de nacimiento, su enseñanza escolar y amistades, aspecto que presumiblemente debió hacerle albergar una gran afinidad.

En cualquier caso, nos interesa especialmente la imagen de Hernández que el propio Mojica interioriza y así hace constar en la citada investigación. A grandes rasgos, "La religiosidad de Miguel Hernández y su poesía” es un repaso a medio camino entre lo biográfico y lo poético. Entre las conclusiones más relevantes que Mojica saca en claro es el declive de la religiosidad de Miguel Hernández a raíz de su segunda llegada a Madrid y su amistad con Pablo Neruda. Esta "consciente religiosidad" en la primera parte de su vida (Mojica, 1978, 111) acerca estos poetas en cuanto tienen un elemento común como es el "autodidactismo", los dos autores "se crearon una cultura propia al margen del mundo académico" (Español, 2012, 25). (Sea como fuere, y como veremos más adelante, Vicente Mojica no solo se interesó por el ámbito religioso de Hernández. Sino que la preocupación por los pobres y la defensa de los más débiles tiene su justa importancia en la inflexión de la trascendencia que señalamos más abajo).

Como parece obvio, Vicente Mojica dedica algunas composiciones a Miguel Hernández a lo largo de su trayectoria. Un ejemplo puede ser el poema "Canción del llanto" (1990, 123124) del libro La paz nos esperaba (1966) y que todavía guarda celosamente las distancias ante la censura y la vigilancia de las autoridades franquistas: "A la memoria de Miguel Hernán- dez, poeta de Orihuela y de España”. Se trata de un ditirambo que versa sobre la gloria del poeta $y$, a su vez, lamenta profundamente las circunstancias de su muerte: "Pastor de la hermosura en que me abraso / dime en qué prado estás, creciente y puro”. Otro caso es "Azahar de tu ausencia" (1990, 173-174) de Palabras de mi amor y mi destino ${ }^{13}$, donde a propósito de la llegada de la primavera, la naturaleza cobra vida y se muestra huérfana ante la ausencia de su compañero más fiel: "Levántate, Miguel, que están la tierra / y el corazón en flor”.

Otras figuras relevantes en la poesía de Vicente Mojica son Antonio Machado y Juan Ramón Jiménez. La presencia de estos dos puntales de la poesía española moderna responde a la automatización de un tópico en la poesía del alicantino que tiene que ver con su lenguaje. El propio Mojica (en Molina, 1973, 100) hace suya la lección de Antonio Machado (Valero Gómez, 2010) y se sitúa junto al maestro a la hora de escoger un "lenguaje elemental y puro" en el que "importa más la precisión” y "una voz delgada y sencilla". A lo largo de sus primeros poemas recogidos en Llamada al corazón (1958) se hace evidente un sentimiento juvenil centrado en la ternura, como puede ser el caso del poema que da título al libro:

Llego a tu corazón día tras día, con mi dolor a cuestas y mis penas, encadenado al llanto en qué cadenas desde mi antigua soledad sombría.

\section{Llamo a tu corazón con qué porfía,} con qué ternura que en tu amor estrenas; llamo a tu corazón desde mis venas con la amargura de mi voz baldía. (Mojica, $1990,45)$

\footnotetext{
${ }^{13}$ Vicente Mojica Benito, Palabras de mi amor y mi destino, Alicante, Caja de Ahorros Provincial, 1971.
} 
Los inicios de Mojica se caracterizan por una delicada sensibilidad y un perfeccionamiento del verso que se dirige, primero, hacia un refinamiento preciosista y, segundo, hacia una condensación expresiva. Vicente Ramos (1990, 18-21) recoge esta renuncia a la retórica y añade que emplea estrofas "coloquiales, plenas de ternura y belleza" (1979, 306). Por ejemplo, la composición inicial de Palabras de mi amor y mi destino (1971) es una buena muestra de ese tono (digamos) entre campechano y sencillo que ha ganado en fluidez:

Si digo rosa o niño, hermano, beso, paz otra vez, ternura, risa, abrazo, o digo Dios, azul, jardín, España, o simplemente árbol, es porque tengo un pozo de agua clara donde sumerjo el corazón, lo baño, $\mathrm{y}$ es de un agua divina que me viene no sé por qué hondos, deliciosos caños, ni por qué ocultas, silenciosas vías, de internas lluvias que me están mojando. (Mojica, 1990, 157)

Por otro lado, la presencia de Juan Ramón Jiménez no puede atribuirse a una interpretación errónea de la fenomenología en el poeta de Moguer (Gracia, 1980, 162). Sino que existe una aproximación más transparente relacionada con la claridad y la desnudez de artificios. Finalmente, y a partir de 1976, puede decirse que Vicente Mojica vive una madurez literaria gracias a la cual logra las mejores composiciones de su trayectoria poética. Este periodo fi- nal es el mejor ejemplo de la expresión serena y pausada del poeta que ha luchado por pulir su técnica. Véase como ejemplo "Árbol mío de ayer" en Árbol de mi sombra (1976):

Hoy es ayer.

En mí ha resucitado

y estoy, niño otra vez,

bajo la sombra

del árbol paternal.

Los claros pasos

de la madre,

su voz,

su inconfundible

y acariciante voz nos acompaña.

Padre es igual que un árbol.

No le pidáis

demasiadas palabras.

Él es un árbol

crecido en el sudor. (Mojica, 1990, 235)

\section{TRASCENDENCIA E INFLEXIÓN DE LA VIGILIA}

A la luz de lo dicho hasta ahora y de su vasta producción pueden establecerse tres etapas bien diferenciadas: 1) Una primera que va desde 1958 a 1968 y que recorre Llamada al corazón, Geografía del llanto y La paz nos esperaba. 2) Un segundo periodo que alcanza el periodo 19691976 y que está conformado por Cancionero desde la tierra a Dios ${ }^{14}$, Palabras de mi amor y mi destino y Detrás de las palabras ${ }^{15}$. 3) Y una última etapa que se desarrolla entre los años 1976 y 1989, y que está compuesta por los libros Árbol de mi sombra, Al pie de la esperanza ${ }^{16}$, Libro de las tribulaciones ${ }^{17}$ y Espejo de la consumación.

\footnotetext{
${ }^{14}$ Vicente Mojica Benito, Cancionero desde la tierra a Dios, Palencia, Rocamor, 1969.

${ }^{15}$ Vicente Mojica Benito, Detrás de las palabras, Málaga, El Guadalhorce, 1973.

${ }^{16}$ Vicente Mojica Benito, Al pie de la esperanza, Alicante, Instituto de Estudios Alicantinos, 1979.

${ }^{17}$ Vicente Mojica Benito, Libro de las tribulaciones, Alicante, Caja de Ahorros Provincial, 1981.
} 
Como ya se ha visto, la poesía de Mojica se caracteriza por un lenguaje sencillo y revelador que está puesto al servicio de una misión pedagógica, en este caso católica. Puede que, efectivamente, la ética estética de Vicente Mojica se articule en "restaurar lo primario divino", "evangelizar esa Restauración” y "elementalizar" o "purificar el lenguaje" (Gracia, 1980, 166). En cualquier caso, predomina un sentimiento religioso que se extiende gracias a diversos elementos relacionados con el mensaje de la Iglesia y que se aglutinan bajo el concepto de trascendencia. Y no es solo que "Dios está presente a lo largo y ancho de toda la obra publicada de Mojica, no en vano estamos ante uno de nuestros más destacados poetas religiosos" (Porpetta, 1981, 13), sino que posee una "forma personal de abordar a Dios en su poesía” (Español, 2012, 12). Aunque en todo caso resulta desmesurado afirmaciones como que Vicente Mojica es un "renovador del misticismo español del siglo XX" (33). En este sentido, un libro relevante es Cancionero desde la tierra de Dios (1969), ya que el poeta plasma un lugar idealizado $\left(L^{\prime} \text { Esplai }\right)^{18}$ y desarrolla una poesía esencialmente natural que le permite proseguir su conversación con Dios, así como utilizar formas religiosas tales como villancicos o composiciones navideñas:

\author{
Desde la iglesia, \\ anillada de pueblo, \\ el campo y Dios tan cerca, \\ mi corazón tan lejos.
}

La verde lejanía del olivar.

Por sus sendas mi alma soñando va. (Mojica, 1990, 136)

Vicente Mojica se nos presenta en sus poemas como un hombre humilde, con los pies en la tierra y muy lejos de una imagen enaltecida del poeta, que "antepone su Dios a su poesía" (Gracia, 1980, 162) porque es "el centro de su vida y de su arte" (Español, 2012, 12): "Dame el nombre, Señor, la voz precisa / con que Tú bautizaste cada cosa" (Mojica, 1990, 96). El planteamiento del poeta alicantino conecta directamente con la poesía española escrita durante los años siguientes a la finalización de la guerra.

Como es sabido, la primera poesía de posguerra entiende arte y espíritu unidos, de tal manera que la poesía se convierte en revelación (Iáñez, 2008, 624-626) ${ }^{19}$. Por citar un ejemplo, la revista Escorial desarrolla un esencialismo espiritualizado que fue evolucionando desde el neoclasicismo a un neorromanticismo apasionado (706). Leopoldo Panero o Luis

\footnotetext{
${ }^{18} \mathrm{~L}$ 'Esplai es la casa (entiéndase de campo, a la que suele referirse como finca o huerto) que Vicente Mojica poseía en el barrio alicantino de Vistahermosa. Este enclave físico protagoniza buena parte de la producción literaria del poeta alicantino, fundamentalmente aquella que, como hemos señalado, versa sobre la naturaleza. Del mismo modo, y a propósito de la lectura de Vicente Mojica en la poesía española de posguerra, el tema del paisaje entrelazado con el amor y el sentimiento religioso es una constante en revistas como Escorial y Garcilaso.

${ }^{19} 1942$ puede representar una primer frontera a la hora de diagnosticar una vuelta a lo religioso singularizada por dos signos de influencia: la "asimilación de la tradición cultural religiosa del XVI, actualizada y vinculada a la cultura de preguerra con replanteamientos formales", que puede estar representada por Gaos, Dámaso Alonso o Bousoño; y por otra parte, "una corriente de poesía religiosa sujeta a moldes clásicos, con una hipervalorada preocupación formal, predominante por entonces", como pueda ser la de Vivanco, Rosales, Pemán o Manuel Díez Crespo (Rubio, 1973, 462). En una vertiente, la oportunidad del centenario de San Juan de la Cruz que, como modelo de hombre y de época (Wahnón, 1987, 415-416), sirve para iniciar un camino de vuelta a la concepción liberal del arte. Mientras, en otra, la recuperación de Unamuno como poeta religioso inicia toda una tendencia "existencial-religiosa” (Rubio y Falcó, 1981,7).
} 
Felipe Vivanco dejan por un momento el sentimentalismo del discurso dirigido a la amada para asentar su intimidad desde "la mirada de Dios" y el tiempo plácido. El hombre esencial, enviado por Dios, construye la intimidad en armonía con los días áureos y plácidos por la gracia divina, así como con el amor. Aunque existen muchos ejemplos a la hora de citar, Tiempo de dolor de Luis Felipe Vivanco puede condensar perfectamente la importancia del sentimiento religioso durante estos primeros años de posguerra, así como la exposición de una vida que consiste en un camino de perfección, gozo y martirio que tiene como último objetivo alcanzar la redención divina.

Si prestamos atención a las palabras que Vicente Mojica (1986) dedica al libro de Ángel Barquilla titulado Ceremonial con la luz del alba $a^{20}$, caeremos en la cuenta de que propone la poesía como uno de los caminos que el hombre tiene para llegar a Dios. Es más, entiende al hombre como una creación que solo "ve saciada su sed de infinito" con el hallazgo de Dios (11). Llegados a este punto, nos topamos con la trascendencia, un concepto que no solo explica la relación directa que hemos señalado entre la primerísima poesía española de posguerra y Vicente Mojica, sino que aporta el basamento primordial sobre el que se articula toda su producción literaria. Esta trascendencia tiene su principal razón de ser en que toda su poesía consiste en el "coloquio mudo que se establece entre el hombre que se eleva y Dios que sale a su encuentro" (Mojica, 1986, 11).

Este proceder puede considerarse "un automatismo" (Gracia, 1980, 162) que el poeta emplea constantemente para lograr dicha trascendencia, para convertirse en "el hombre que se eleva, aquí es el poeta” (Mojica, 1986, 11). Todo este planteamiento conecta con el significado más visible de la definición del acto poético que Mojica lleva a cabo: "para mí, la poesía es una constante permanencia en vigilia” (Mojica, en Molina, 1973, 99). En este sentido, la poesía es aprehendida como un estado de permanente espera al diálogo y llegada de Dios; o bien, como una mera oración litúrgica para alcanzar dicha trascendencia. El poema “Mañana, hoy, ahora” de Árbol de mi sombra (1976) puede ser una buena muestra:

Tú, yo, cualquiera de nosotros, mañana, hoy, ahora, en este mismo instante, podría suceder que se encontrara inesperadamente, de pronto, frente a Dios.

Decid, decidme quién entonces tendría tiempo de lavar sus manos, quién podría desteñirlas de culpa, lavar su corazón. (Mojica, 1990, 262)

En la otra cara de la moneda nos encontramos con una dimensión de la poesía como "constante permanencia en vigilia" que conduce este discurso hacia nuestro propósito, la vigilia como inflexión. Como veremos en las próximas líneas, la vigilia también puede referirse a las dudas de fe que muestra el poeta $y$, en consecuencia, a todo un aparato ideológico que configura una visión muy particular de su cristianismo. Antes de nada, y a pesar de la citada aproximación entre Mojica y el panorama poético de la primerísima posguerra, cabe advertir que el poeta alicantino no se posiciona

${ }^{20}$ Ángel Barquilla Ramiro, Ceremonial con la luz del alba, Alicante, Caja de Ahorros Provincial de Alicante, 1986. 
en ningún momento con el ideario nacional o pone su pluma al servicio de la dictadura franquista, como así ocurre en muchos casos durante los primeros cursos de los años cuarenta.

La poesía de Mojica no se compone exclusivamente de una perspectiva católica, sino que "no rehuye el pensamiento" y "expresa sus propias dudas" (Alonso, 2015). O dicho de otro modo, afronta el problema de la trascendencia de Dios sin evitar cuestiones referidas a la condiciones sociales de la España de posguerra o a las propias vacilaciones del ánimo espiritual. Desde luego, "no pierde la fe, aunque pueda sufrir el tormento de la duda" (Español, 2012, 12). Pueden encontrarse muchas muestras de ese distanciamiento e interrogación propia, aunque es la segunda etapa de su trayectoria (1969-1976) -y más concretamente el libro $\mathrm{Pa}$ labras de mi amor y mi destino (1971)- donde se intensifica con mayor notoriedad. Por ejemplo, "En plena oscuridad" es un texto crucial:

Enciéndeme una luz. Cómo es posible que permitas que vaya como un ciego, tropezando, cayendo, tropezando, en plena oscuridad, con ambas manos extendidas, buscándote angustiado, y que te escondas, Señor, de mí y te calles, cuando te estoy llamando desesperadamente, como un niño extraviado en la noche, que grita y llora porque busca a su padre y no lo encuentra. (Mojica, 1990, 159)

El poeta, en plena consonancia con la angustia existencial de los autores de su quinta (Valero Gómez, 2013, 77-80), se encuentra perdido, busca una luz a la que aferrarse y pronuncia un grito desgarrador:

\author{
En plena oscuridad, Señor; se apagan \\ ya las últimas luces, \\ agonizan \\ con temblores de frío \\ en mis esquinas, \\ y te llama aún mi voz, te está llamando.
}

Dame una luz, solo una diminuta señal, como un resquicio por donde ver tu resplandor y hallarte. (Mojica, 1990, 159)

Tan solo por un momento la voz del escritor alicantino se siente abatida: “y será todo inútil, / y seré ya incapaz / de perseguir y de encontrar tus huellas" (Mojica, 1990, 160). El poemario citado prosigue este pulso gracias a composiciones como la siguiente, que lleva por título "Cómo sabré, Señor...":

¡Cómo sabré, Señor, cómo he de hallarte, saber que Tú eres, ver que tus huellas de ternura coinciden plenamente con las divinas señas de Dios que se ha hecho Niño!<smiles>[AlH2]</smiles>

¿Cómo he de hallarte, pues, qué nueva estrella,

como señal de amor que busco en vano, he de esperar para encontrarte, verte, saber que eres el Verbo ya hecho Carne?

¿Me lo dirán el pájaro y la rosa?

¡Avísame, Señor, haz que una brisa, que un leve soplo tuyo, un beso alado, me inunde tiernamente

y en mi sangre resuenen tus campanas! (Mojica, 1990, 161) 
Las dudas no se terminan en una mera resignación. Mojica persigue el diálogo de antaño e interpela directamente a ese Dios que como en Al pie de la esperanza (1979) es redención e inspiración. Finalmente, Palabras de mi amor y mi destino (1971) se resuelve con un regreso al camino de la fe: "Descansa ya, Señor, tómame el pulso, / comprueba que no tiemblo" (Mojica, 1990, 164).

Para el poeta alicantino, la duda es ante todo un "tormento" (Español, 2012, 12) que hace tambalear la realización de su vitalismo poético. Como hemos visto, esta otra parte de la vigilia supone una inflexión porque, principalmente, estas dudas son consecuencia de las injusticias y desigualdades de las que el poeta es testigo durante la posguerra española. Recordemos que Vicente Mojica nace en un entorno de absoluta pobreza y que pese a las penurias económicas rechaza el amparo de un matrimonio adinerado (Vicente Otero Gozálvez y su mujer) para forjarse él mismo su educación y desarrollo profesional. De igual manera, la señalada devoción por Miguel Hernández (Mojica, 1978) o Antonio Machado son buenas pistas para abordar la inflexión de la vigilia.

El investigador Manuel Parra Pozuelo (2008) ha realizado un interesante estudio titulado "El primer poema de Vicente Mojica y otras apariciones en su obra del tema de la ciudad bombardeada”. Esta publicación refleja la importancia del primer poema de Vicente Mojica, "Bilbao, la mártir" en la revista Socorro Rojo Internacional ${ }^{21}$ durante el año 1937, y da buena cuenta de su participación en el bando republicano durante la guerra:
¡Entregad la vida, vascos

antes de que pase el fascio,

más vale morir de pie

que morir arrodillados!

¡Viva la mártir Bilbao!

¡Viva la brava ciudad

que derramando su sangre

defiende la libertad! (Mojica, en Parra, 2008, 70-71)

Por entonces, el poeta solo cuenta con catorce años y se le encargan trabajos para el diario Nuestra Bandera, mientras es afiliado a la Unión General de Trabajadores. Es curioso, al mismo tiempo que sintomático, que este poema haya sido excluido de la Obra poética (1990) que reúne toda su producción lírica.

Esta composición es una buena piedra de toque a la hora de profundizar en la inflexión de la vigilia y la cara menos visible que engloba la trascendencia divina. Queremos decir, en otras palabras, que la poesía de Vicente Mojica presenta una tensión de fondo evidente entre este continúo coloquio con Dios y los temas puramente sociales. La primera (19581968) y última etapa (1976-1989) de la producción poética de Mojica presenta signos claros de una preocupación política y social que, en todo caso, no imposibilita o invalida su esencialidad católica, sino que la hace posible en tanto en cuanto no responde más que a una depuración de su inicial frentepopulismo (véase "Bilbao, la mártir" y su vinculación ideológica) hacia una preocupación por el ser humano que no deja ser generacional y de corte religioso.

\footnotetext{
${ }^{21}$ Para más detalles sobre esta publicación proponemos consultar Moreno Sáez (1994, 173-176). De la revista del Socorro Rojo Internacional se publican 21 números entre el 13 de marzo de 1937 y enero de 1938. A la hora de citar dicho poema, empleamos Parra (2008). Cabe advertir, en último lugar, que la difusión de dicho órgano tenía un impacto internacional. Quiere decirse, en consecuencia, que una composición como la del joven Mojica, tan solo catorce años, adquirió una repercusión inimaginable para aquella época.
} 
Y esta tensión, como hemos visto, se presenta mediante varias formas y desde sus principios. Sus primeros poemarios -Llamada al corazón, Geografía del llanto y La paz nos esperaba, aquellos que componen la primera etapa (1958-1968) - inician esta línea estética menos reconocida. Por ejemplo, Llamada al corazón combina una primera parte destinada a la ternura de la amada, al hallazgo de Dios o al ambiente familiar del hijo y la amistad con una segunda parte gobernada por un tono reivindicativo y verdaderamente crudo. Hacemos hincapié en esta inflexión y en esta otra parte de la moneda de la vigilia porque, sin lugar a dudas, es un ámbito de la poesía de Mojica que no se ha estudiado. Aquello que dijimos más arriba acerca de leer en defensa propia (García, 2012) y la automatización de Vicente Mojica como un poeta netamente católico. De este modo, un poema como "Llamada a las conciencias" (Llamada al corazón) da el pistoletazo de salida a esta tensión mediante el tema de la pobreza en la infancia: "niños igual de niños que nuestros propios hijos, / sin que nadie les vista ni les tienda una mano" (Mojica, 1990, 54).

A este, le siguen otras composiciones con títulos bastante clarificadores como "Emigrante" o "Canto a la verdad". Especial importancia tienen los dos últimos poemas, "Llamada inútil" y "Voz fiel al sentimiento". "Llamada inútil" se apoya en una relevante cita de Eugenio de Nora ("Es tiempo de no plantar rosales. Acordaos") y expone con claridad la vertiente socialmente comprometida contra la dictadura:

Oh, no, ya no, Poeta, hoy ya no es tiempo de cultivar las rosas; se alzan las bayonetas con un aliento de odio al amor dirigido y un brotar de amapolas en sus filos espera.
Una ausencia de rosas, habitada de cardos, tiene el aire de angustia de la atmósfera densa

y una enorme cosecha de muertes en racimos

por un cielo de cuervos se presiente muy cerca. (Mojica, 1990, 58)

Estos versos acompañan a "Voz fiel al sentimiento", dedicado a un poeta de clara ascendencia frentepopulista como Manuel Molina y con claras referencias a la situación de los intelectuales por aquellos años:

Estáis todos callados, mudos como los muertos.

Y bajáis la cabeza de Vergüenza porque pensáis lo mismo que yo pienso.

Porque guardáis podridas las palabras, mascullando en silencio todas vuestras desdichas que no decís por miedo. (Mojica, 1990, 61)

Debe reconocerse la valentía y la honradez de Vicente Mojica a la hora de llamar las cosas por su nombre y arremeter, si su conciencia considera necesario, contra todos aquellos arribistas intelectuales -o no intelectuales- que se mantienen callados frente a las tropelías de la dictadura.

El análisis concienzudo de la línea más comprometida de Vicente Mojica permite precisar su demarcación ética estética. Ya hemos visto que su tradición católica y neoclasicismo le sitúan junto a la vertiente más religiosa que se desarrolla en los años cuarenta. Sin embargo, que "el sujeto de su poesía" sea "siempre el Hombre", "sencillo y concreto, forjado a mar- 


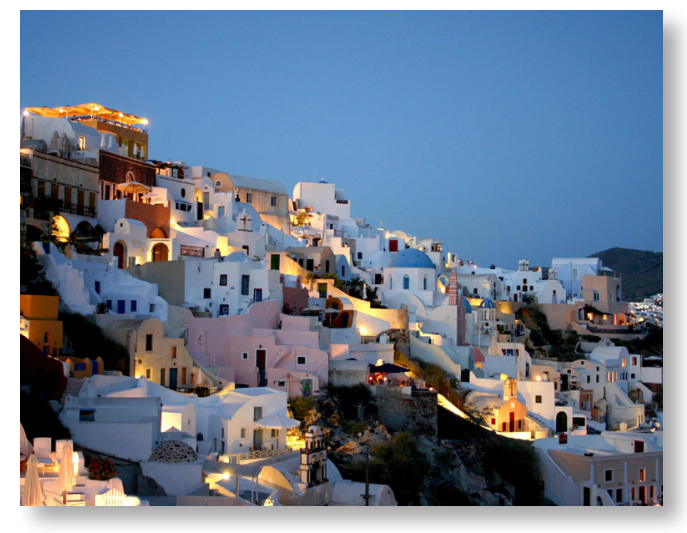

tillazos" (Español, 2012, 32) obliga a abrir el abanico y situar a Vicente Mojica en esa diáspora que se produce en el panorama poético español en torno al año 1944 (Prieto de Paula, 1991). Aunque con casi una década de retraso, la poesía del alicantino también pertenece a ese mapa estético en el que quedan reflejados la conjugación del rescate de Unamuno, así como la rehumanización mediante los temas de Espadaña y la apuesta, principalmente de Corcel, por el neorromanticismo.

La situación tiene mayor calado desde el punto de vista histórico, puesto que si España vive una situación de posguerra, a su vez, el desenlace de la Segunda Guerra mundial marca esta coyuntura. Sin lugar a dudas, y finalmente, se trata de un clima donde se suman un modelo religioso y la reacción contra este formalismo y neoclasicismo mediante el neorromanticismo acorde con "el propio tiempo cultural que se vivía" y con el auge de la filosofía existencial (García de la Concha, 1987, Vol. II, 609). La cita de Eugenio de Nora es más que sintomática, ya que el poeta de Espadaña junto a Blas de Otero principalmente abren las puertas del existencialismo hacia la poesía social. Digamos, como resumen, que Vicente Mojica refleja la influencia de todo este clima rehumanizador producido durante los años cuarenta y al que llega tarde -por edad y residir en provincias- aunque en ningún caso alcanza la poesía social, aquí se detiene su territorio ético estético.

Este pulso estético prosigue durante la citada primera etapa. El libro Geografía del llanto (1963) alimenta este didactismo social gracias a una "muestra de sentimiento terrenal" (Molina, 1973, 89). No olvidemos que Vicente Mojica también entiende la poesía como una misión evangelizadora. Si la anterior entrega se apoyaba en el amor, ahora es la esperanza quien capitaliza su ética más social. Geografia del llanto posee una notoria madurez y desde el primer texto asienta una visión cristiana que no se desentiende de la realidad. Sin lugar a dudas, el poeta está perfeccionando su propio camino estético. En este sentido, "Desde el silencio" es una de las composiciones más rudas y áridas: "Son muchos muertos un millón de muertos / para olvidar su peso de criaturas. / Llevo un millón de voces que me gritan / desde dentro de mí y de mi silencio, / con mi llanto por todas sus ausencias." (Mojica, 1990, 67). O los siguientes versos que forman parte del poema que da nombre al libro: "Oh, vida, vida, cómo has ido enseñándome / la nueva geografía no aprendida de niño" (Mojica, 1990, 75).

La tensión social de esta primera etapa concluye con La paz nos esperaba (1966), un conjunto textual que está dedicado al tema de España en la Guerra Civil. El poeta afronta la nostalgia y el recuerdo de la guerra gracias a un sentido lírico "con la continuidad y la reiteración de un canto, de una narración musical, elegíaca" (Molina, 1973, 90). La presencia de la muerte, el odio, las banderas o la ciudad repleta de cadáveres son una constante. Otro aspecto muy interesante es el tema de la ciudad bombardeada, apartado que ha sido estudiado por Parra Pozuelo (2008) en su citado artículo. Entre los poemas que desarrollan esta temática 
destaca el texto sin título (Mojica, 1990, 106107) que aborda el bombardeo que sufre el Mercado Central de Alicante el 25 de mayo en 1938, uno de los ataques más crueles y estudiados de la Guerra civil (Pérez Oca, 2005; Iniesta y Coll, 2000; Solé y Villarroya, 2003).

Esta primera etapa deja paso a una segunda etapa de la que ya hemos dicho que destaca el cuestionamiento de la fe. De este modo, nos topamos ante un desarrollo poético que trata de compaginar la tensión fe / injusticia social en su primera etapa, y una segunda dominada por la duda. Las razones para pensar así se basan en que la presencia de Dios en la poesía de Mojica parte de la cotidianeidad, de su "redescubrimiento" constante en la "realidad misma” (Español, 2012, 12). El problema surge cuando el poeta vive rodeado por una realidad huérfana de la bondad y del amor que propugna en sus versos. Es decir, la problemática social (debido a la injusticia, el hambre, el odio, la muerte o las desigualdades) trae consigo el otro significado que proponemos para la poesía como "constante permanencia en vigilia": la vigilia como inflexión, como duda de la trascendencia ante la crueldad social.

Esta problemática se resuelve poco a poco en la segunda etapa hasta alcanzar la plenitud ética y estética de la tercera etapa. Un libro como Árbol de mi sombra (1976) representa la integración de estos dos polos. A partir de ahora, los poemas que muestran una preocupación social se visten de un mensaje luminoso y esperanzador, se hace presente la intención didáctica y evangelizadora. "Mensaje de urgencia", "Pueblo" o "Palabras inútiles" son muestras de esta síntesis entre el poema de urgencia y el mensaje religioso. Mojica, incluso, interpela directamente a una sociedad civil que considera "autómatas" y "esclavos del reloj", véase sino el poema "A vosotros os digo"
(Mojica, 1976, 28-29). Otro texto como "El compromiso" deja claro que sus convicciones albergan profundos lazos católicos: "El hombre es quien me duele, / ¡quien siempre me ha dolido!" (Mojica, 1976, 30).

Más que nunca, Mojica expresa su solidaridad e interés exclusivo por la existencia del ser humano, según la poesía escrita durante los años cuarenta en España. Ello puede verse en el vitalismo renovado de $\mathrm{Al}$ pie de la esperanza (1979), el talante humanista de Libro de las tribulaciones (1981) o la perfección personal de Espejo de la consumación (1987). Queda instaurada así una de las nociones de compromiso más peculiares de la poesía española de posguerra, allí donde el propio poeta alicantino habla de compromiso para la poesía religiosa del Padre Ángel Barquilla (Mojica, 1986, 12) o aquello que Vicente Ramos (1990, 1819) tanto teme afrontar cuando lo define como “ámbito sociológico" o "politicismo". Sin lugar a dudas, un reflejo sincero e ilustrativo de la coyuntura histórica reciente de este país.

\section{MAGISTERIO Y ORBE: UNA MIRADA HA-}

\section{CIA DELANTE}

De carácter "infinitamente generoso" y muy "accesible" a las inquietudes de los autores más jóvenes (Alonso Ruiz, 2015; 2008; Ferris, 2008), Vicente Mojica no solo comparte una orientación poética con aquellos con los que convivió (Manuel Molina, Ernesto Contreras, Vicente Ramos, Joan Valls Jordá, Julián Andúgar, etc.), sino que -como veremos en las próximas líneas- ha marcado una línea ética y estética en el desarrollo ulterior de la poesía alicantina. El propio Vicente Mojica establece en su poética para la Antología de la Poesía alicantina actual (1940-1972) de Manuel Molina $(1973,100)$ los ejes principales de su poesía: 1$)$ su experiencia "primera" y "vital trascendente" 
de la guerra como niño-poeta; 2) la "semilla" de su formación en colegios religiosos (destacan los salesianos) y la doctrina de Cristo; y 3 ) la "influencia decisiva" de "mis raíces humildes y entrañables, los medios escasos, la necesidad de los míos" para sentirse al lado de los "más necesitados".

Este pequeño esquema, así lo considera el propio autor, es un resumen muy breve de todas las pautas y pormenores que hemos señalado más arriba a propósito de la poesía de la vigilia. A continuación, nos proponemos apuntar algunas pinceladas sobre la continuidad y reflejo que ha tenido el escritor alicantino en las promociones siguientes. De este modo, vamos a hablar principalmente de tres autores que no solo dejan constancia de su admiración hacia Mojica, sino que, al formar parte de tres generaciones distintas, dejan entrever la influencia y recorrido de su magisterio poético en el tiempo. El primero de ellos, Ángel Barquilla Ramiro, nace en 1938 en Romangordo (Cáceres) y fallece en Castellón en el año 2004. Desde los años setenta, vive largas temporadas y frecuenta su residencia en Alicante debido a su dedicación a la orden agustiniana.

La obra del Padre Ángel Barquilla se compone principalmente del citado Ceremonial con la luz del alba (1986), Sendero de esperan$z a^{22}$, Nanas para el niño Dios ${ }^{23}$, Silabario de preguntas. Poesías ${ }^{24}$ más Y la palabra se hizo verso $^{25}$. Como ya hemos destacado, Mojica facilita la publicación de Ceremonial con la luz del alba en el servicio editorial de la Caja de Ahorros Provincial de Alicante, así como realiza un prólogo a la edición. Damos por hecho, en cualquier caso, que entre Mojica y Barquilla existe una amistad que parte de sus creencias religiosas. El prólogo en cuestión, "La poesía del P. Ángel Barquilla Ramiro” (Mojica, 1986), destaca las mayores virtudes del poeta agustino y realiza una lectura destacable de aquellos aspectos que aproximan las dos trayectorias. Por ejemplo, el concepto de trascendencia es un elemento recurrente en Ángel Barquilla y puede verse en el siguiente poema titulado "Acechando tus pasos":

Aquí me tienes, Dios, puesto al acecho, oteando a lo lejos tu camino

por ver si entre las brumas adivino

tu firme caminar por mi barbecho. (Barquilla, 1986, 22)

La utilización de estructuras como el soneto y la fluidez del verso invitan a estudiar esta relación más en profundidad. Además, el sentimiento religioso se vertebra gracias a la alegría por la llegada de Dios y la presencia de la luz. También se utilizan fórmulas de marcado carácter religioso como los salmos, las oraciones, las epístolas o los credos. En cualquier caso, parece evidente que estos poetas forman parte destacable de la poesía mística desarrollada en el panorama alicantino desde la posguerra hasta nuestros días.

Otro poeta del que ya hemos hablado y posee una conexión indudable con Vicente Mojica es Francisco Alonso Ruiz. Nacido en la ciudad de Alicante en 1948, ha participado en multitud de iniciativas artísticas de la capital, como cine, teatro, radio e incluso el ambiente

\footnotetext{
22 Ángel Barquilla Ramiro, Sendero de esperanza, Zamora, Ed. Montecasino, 1988.

${ }^{23}$ Ángel Barquilla Ramiro, Nanas para el niño Dios, Madrid, Revista Agustiniana, 1991.

${ }^{24}$ Ángel Barquilla Ramiro, Silabario de preguntas. Poesías, Madrid, Revista Agustiniana, 1999.

${ }^{25}$ Ángel Barquilla Ramiro, Y la palabra se hizo verso, Madrid, Revista Agustiniana, 2006.
} 
fogueril. Como ya hemos señalado en varios estudios al respecto de su obra (Valero Gómez, 2011; 2012; 2013), la poesía de Francisco Alonso precisa ser ordenada y publicada en las condiciones que su calidad merece. Hasta el momento, contamos con escasamente cuatro publicaciones: Acento humano ${ }^{26}$, la plaquette que logra publicar con apenas veinte años y gracias al patrocinio de su madre; Testimonio de tiempo ${ }^{27}$, que gestiona Vicente Mojica en la Caja de Ahorros Provincial de Alicante; Soledad de alma ${ }^{28} \mathrm{y}$, recientemente, Cuaderno de ahora mismo ${ }^{29}$. También merece la pena señalar que ha publicado en numerosísimas revistas y antologías, destacando entre todas ellas su inclusión en la revista IEA (Instituto de Estudios Alicantinos), en el número dedicado a la poesía joven de la provincia de Forma abierta (número 12, 1981, suplemento de la revista Instituto de Estudios Alicantinos) y, en último lugar, la antología sobre cuatro poetas alicantinos que lleva por título El tiempo de los héroes ${ }^{30}$.

El propio Francisco Alonso (2008; 2015) ha contado cómo nace su amistad con Vicente Mojica, de hecho juega un papel importante en el homenaje que la revista alicantina AUCA celebra en su honor en el año 2008. Su poesía ha sido definida como "corporal" y en pleno diálogo con la "sustancia que impregna la naturaleza y los objetos" (Zapata, 2012, 44). Desde luego, esta definición se refiere a una lectura global de su poesía - nosotros mismos la hemos definido de resistencia (Valero Gómez, 2011)- y que principalmente explica los derroteros hacia dónde se ha dirigido esta. Sin embargo, conviene regresar a los inicios de la poesía de Francisco Alonso Ruiz para encontrar qué pudo impresionar a Vicente Mojica y, en consecuencia, tenderle su mano amistosa.

La primera producción poética de Alonso Ruiz (pongamos por caso, desde 1969 hasta 2001) está gobernada por unos interrogantes que se debaten entre la fe, el dolor del ser humano y la utilidad / inutilidad de la propia existencia. Acento humano (1969), su carta de presentación, adelanta la presencia de la muerte como uno de los temas más importantes de su poesía: versos como "marcado por la muerte, lucho y vivo" o "hay que morir un poco cada día” son buena muestra de ello. Sentimientos tales como el dolor, el miedo y la angustia recorren esta primera entrega. No obstante, el libro se presenta como una "búsqueda, a través de la muerte, de Dios y de la vida”, según reza la presentación del autor. Ya pueden advertirse algunas huellas (los sonetos dedicados a Miguel Hernández y el desarrollo clásico de las composiciones) de aquello que más pudo interesar a Mojica en su poesía. Al respecto, Dios (o el Señor) aparece como un interlocutor, a veces asumido y otras reclamado, que no es más que un testigo directo del sufrimiento del poeta, que no es más que el testimonio del sufrimiento de todos los hombres. El último poema, "Oración antes de morir", es desgarrador:

He perdido, Señor, esta batalla porque tu omnipotencia me ha vencido. A tus pies derrotado y abatido, sin nada que decir, mi voz se calla.

\footnotetext{
${ }^{26}$ Francisco Alonso Ruiz, Acento humano, Alicante, edición del autor, 1969.

${ }^{27}$ Francisco Alonso Ruiz, Testimonio de tiempo, Alicante, Caja de Ahorros Provincial de Alicante, 1982.

${ }^{28}$ Francisco Alonso Ruiz, Soledad de alma, Elche, Lunara, 2001.

${ }^{29}$ Francisco Alonso Ruiz, Cuaderno de ahora mismo, Alicante, Presencias Aucanas, 2012.

${ }^{30}$ Manuel Valero Gómez, El tiempo de los héroes. Cuatro poetas alicantinos, Alicante, Aguaclara.
} 


\section{$[\ldots]$}

Ya mírame, Señor, lleno de miedo

esperando la muerte gota a gota

para gozar de tanto amor, Dios mío. (Alonso, $1969, \mathrm{~s} / \mathrm{n}$ )

Recordemos que, por entonces, el poeta cuenta con apenas veinte años. Más adelante, en el tramo de tiempo que alcanza hasta Testimonio de tiempo (1982), Francisco Alonso escribe un extenso conjunto textual que será el que entregue a Mojica y le ayude a publicar en la Caja de Ahorros Provincial de Alicante. Según las palabras del propio Alonso Ruiz, y a la luz del prólogo "Un nuevo nombre en la poesía alicantina”, Vicente Mojica $(1982,9)$ destacó del joven autor su "formación más humana que científica", su preocupación por las miserias humanas y su "riqueza de innatas intuiciones, de aciertos asombrosos" con la "frescura y la gracia de la espontaneidad, de la sencillez, de la incontaminación de corrientes nuevas y experimentales".

Testimonio de tiempo cierra una primera etapa de la producción poética de Alonso que concluye con el final del siglo XX. Estos poemas no hacen más que recalcar que la tragedia del ser humano reside en su soledad frente a la existencia. Y de algún modo, como ya anuncia Acento humano, el poeta se mantiene en rebeldía ante un Dios que no acude a su súplica de auxilio. Testimonio de tiempo es el descubrimiento de una realidad íntima consagrada al replanteamiento del modelo existencial que ha sufrido el propio autor, hablamos de una formación religiosa a consecuencia de la dictadura, del entorno familiar y de sus propios intereses. Quizá, las mayores diferencias entre Mojica y Alonso se encuentran en que, este último, ha optado por la conformación de esta subjetividad en la que el propio poeta asume la creación de un Dios íntimo: "Siento a mi Dios oculto que me llama / a través de la noche o el vacío" (Alonso, 1982, 29). El ambiente sórdido, esa atmósfera oscura, que está presente en el tono general de su poesía también es un factor relevante.

A partir de aquí, desde los poemas escritos durante los años noventa en adelante y fundamentalmente con el nuevo siglo, Alonso Ruiz supera la conciencia-Dios y su ética estética se dirige hacia la consumación de la tríada naturaleza / ciudad / casa-mundo (Valero Gómez, 2012, 8). Esta nueva coyuntura poética abre distancia con Vicente Mojica y, ahora, su propuesta se orienta más hacia la intimidad cotidiana, el mundo objetual y urbano. De alguna manera, el poeta rompe las costuras que le unían al corsé del clasicismo y no duda en dejar entrar nuevos aires neorrománticos. Soledad de alma (2001) es un buen reflejo de este cambio de ritmo. Aunque persiste la noche como dolor o la preocupación por el ser humano, Dios aparece definitivamente como culpable y un ser desentendido que, incluso, quiere arrebatarle a su madre: "Golpea, Dios, su corazón. Golpea / el corazón cansado de mi madre”.

Soledad de alma es la piedra angular sobre la que se basa su poesía de madurez (Valero Gómez, 2013, 21), y desde donde puede leerse con asombro la exactitud y sensibilidad de Cuaderno de ahora mismo (2012). La victoria del espacio revivido y doliente sobre la intimidad (Valero Gómez, 2012, 9) nos hace firmar debajo de aseveraciones tales como que la "catarsis diaria" de Francisco Alonso muestra un poeta "nuestro y necesario" (Zapata, 2012, 43). Valga indicar, por último, que podemos encontrar varios poemas dedicados a Vicente Mojica, entre ellos destacan los incluidos en el homenaje de la revista AUCA (2008, 56-62), 
algunos inéditos, aunque siga destacando la composición que abre Testimonio de tiempo, "A Vicente Mojica" $(1982,13)$ : "Poeta de las cosas más cercanas / y más sencillas: yo tu nombre quiero / poner junto a mi nombre en el alero / donde vuelan mis aves más tempranas".

En último lugar, mencionamos el caso del joven alicantino Joaquín Juan Penalva. Oriundo de Novelda, nace en esta localidad en el año 1976, es doctor en Filología Hispánica y trabaja actualmente como profesor de la Universidad de Alicante. Ha publicado varios libros de poesía: Babilonia, mon amour (junto a Luis Bagué $)^{31}$, La tristeza de los sabios ${ }^{32}$, Hiberna, hibernorum ${ }^{33}$ y Anfitriones de una derrota infinita $^{34}$, que ha sido reconocido con el XXXV Premio de poesía de la Crítica Literaria Valenciana. Las dos primeras entregas de Penalva se caracterizan por su fascinación por el cinematógrafo y el culturalismo. En estos títulos no existen rastros a la hora de trazar un paralelismo con la poesía de Vicente Mojica. Aunque, por otro lado, sí que se atisba un didactismo de fondo que, pese a no mostrar la entereza católica que quizá luego alcance mayor vigor, permite aproximar poco a poco a sendos autores.

Caso bien distinto es el de Hiberna, hibernorum (2013), ya que presenta un trasfondo afín al de Mojica. A lo largo de este poemario, Joaquín Juan Penalva realiza un balance de su vida cotidiana apoyándose en el saldo de victorias y fracasos. La voz experiencial y la vida familiar están muy presentes durante todas las composiciones. Destaca, por ejemplo, la alusión constante a los hijos; hecho que nos recuerda la última parte de la trayectoria poética de Vicente Mojica, pónganse por caso el título Al pie de la esperanza (1979). Pero, sin lugar a dudas, donde el magisterio se hace más visible es en el poema que rinde tributo a la memoria del propio Mojica. "Palimpsesto", que incluye la dedicatoria "Para Vicente Mojica, in memoriam", hace visible el gusto del joven escritor:

Ahora que las glorietas

llevan tu nombre,

ahora que los sueños

lamentan tu ausencia,

escucho

la llamada al corazón

que traza

una geografía del llanto

en el lugar

donde la paz nos esperaba. (Juan Penalva, 2013, 27)

En último lugar, Anfitriones de una derrota infinita es una continuación estética de Hiberna, hibernorum. Sigue presente ese paralelismo con el humanismo y la sencillez de Mojica. Quizá, “...Vita Brevis” sea uno de los mejores ejemplos del tono confesional e íntimo donde poesía y vida se confunden:

El mundo es tan grande...

y tanto los libros,

y tantos los sueños...

que cada vez me veo

más pequeño,

más insignificante,

más cercano al suelo,

parte del polvo,

\footnotetext{
${ }^{31}$ Joaquín Juan Penalva y Luis Bagué Quílez, Babilona, mon amour, Murcia, Universidad de Murcia, 2005.

${ }^{32}$ Joaquín Juan Penalva, La tristeza de los sabios, Valladolid, Academia Castellana y Leonesa de la Poesía \& Editorial Azul, 2007.

${ }^{33}$ Joaquín Juan Penalva, Hiberna, hibernorum, Elche, Frutos del tiempo, 2013.

${ }^{34}$ Joaquín Juan Penalva, Anfitriones de una derrota infinita, Madrid, Huerga \& Fierro, 2015.
} 
fragmento de la tierra, promesa de ceniza, certeza de nada. (Juan Penalva, 2015, 51)

Finalmente, y gracias a esta revisión de la obra del poeta alicantino, podría decirse que leer hoy a Vicente Mojica, como a él tanto le gustaba decir, es revivir aquella vieja misión que la poesía cumplía: no más que un estado de vigila, acaso permanente.

\section{BIBLIOGRAFÍA}

- AA. VV. (1975). Narradores alicantinos de 1954. Barcelona: Ediciones Marte.

- Alonso Ruiz, F. (1969). Acento humano. Alicante: edición del autor.

-- (1982). Testimonio de tiempo. Alicante: Caja de Ahorros Provincial de Alicante.

-- (2001). Soledad de alma. Elche: Lunara.

-- (2008). Mi amistad con Vicente Mojica. AUCA, 67.

-- (2012). Cuaderno de ahora mismo. Alicante: Presencias Aucanas.

-- (2015). Entrevista personal celebrada el 22 de abril de 2015.

- Alonso Dávila, I., y Sánchez López, C. (1992). De viva voz: la posguerra en el casco antiguo. "Es que en la posguerra fue peor que en la guerra...”. Alicante: Excmo. Ayuntamiento de Alicante.

- AA. VV. (2008). Monográfico dedicado a Vicente Mojica. Auca de las letras. Revista Literaria y Artística, 14. Recuperado de http://www.cervantesvirtual.com/obra /n-14-noviembre-2008/

- Azuar, R. (1980). Alicante y lo alicantino. Alicante: Publicaciones de la Obra Social y Cultural de la Caja de Ahorros Provincial de Alicante.

- Barquilla Ramiro, P. Á. (1986). Ceremonial con la luz del alba. Alicante: Caja de Ahorros Provincial de Alicante.

- Bautista Belda, V. (1988). Vega Baja. Orihuela: Gráficas Zerón.

- Bauzá, J. (1975). Noticia sobre la generación del horror.

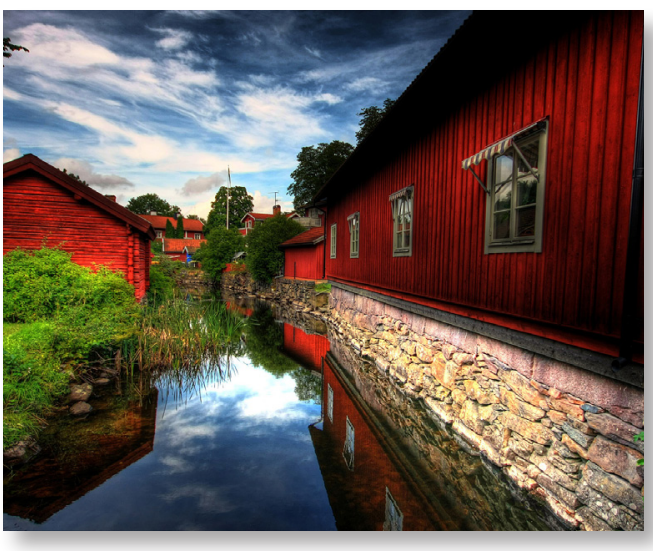

AA. VV., 7-18

- VV.AA. (1989). Cultura y sociedad en Alicante en los años cincuenta. Canelobre, 14/15, Instituto de Cultura Juan Gil-Albert. Recuperado de https://www.iberlibro. com/CANELOBRE-1415-Cultura-sociedad-Alicanteaños/1184884154/bd

- Cerdán Tato, E. (1978). La lucha por la democracia en Alicante. Alicante: Librería Compás.

-- (1992). La estética en el escritor alicantino. Memoria y vicisitud de la iniciación a una estética o como las uvas que reviven en el vino profano. Valencia: Bancaja.

- Chipont, L., y Chipont, E. (1984). Alicante, años cuarenta. Alicante: Gráficas Díaz.

- Español Bouché, L. (2012). Tres poetas alicantinos. Alicante: Editorial Club Universitario.

- Fernández, F. J. (2008). El auto sacramental en Vicente Mojica. Semblanza de El sembrador de vientos. AUCA,14,65-66. Recuperado de http://www.cervantesvirtual .com/obra/n-14-noviembre-2008/

- Ferris, J. L. V. (2008). Espejo de una amistad. AUCA,14, 7-9. Recuperado de http://www.cervantesvirtual.com/ obra/n-14-noviembre-2008/

- García, M. Á. (2012). Leer en defensa propia. El genio maligno. Revista de humanidades y ciencias sociales, 10, pp. 161-168 [en línea].

- García de la Concha, V. (1987). La poesía española de 1935 a 1975. Volumen I. De la preguerra a los años oscuros 1935-1944; Volumen II. De la poesía existencial a la poesía social 1944-1950. Madrid: Cátedra.

- Gracia, A. (1980). Una poética y un tópico desautoma- 
tizado. (Aproximación a M. Molina y V. Mojica). IEA, 30, 153-169.

-- (1989). Diez notas sobre la poesía en Alicante (19501959). Canelobre,14/15, 139-160.

- Iáñez, E. (2008). Falangismo y propaganda cultural en el «Nuevo Estado»: la revista Escorial. Tesis doctoral dirigida por el profesor Dr. José A. Fortes Fernández. Granada: Departamento de Literatura Española de la Universidad de Granada.

- Iniesta Pérez, J. L., y Coll Pujol, J. (2000). Bombardeos del Litoral Mediterráneo durante la Guerra Civil. Valladolid: Quirón Ediciones.

- Juan penalva, J. (2007). La tristeza de los sabios. Valladolid: Academia Castellana y Leonesa de la Poesía \& Editorial Azul.

-- (2013). Hiberna, hibernorum. Elche: Frutos del tiempo.

-- (2015). Anfitriones de una derrota infinita. Madrid: Huerga \& Fierro.

- Juan Penalva, J., y Bagué Quílez, l. (2005). Babilonia, mon amour. Murcia: Universidad de Murcia.

- López Gorgé, J. (1989). Las polémicas literarias de la época. Canelobre, 14/15, 27-32.

- Martínez Morellá, V. (1963). Escritores alicantinos del siglo XX. Alicante: Sucesor de Such, Serra y compañía.

- Mojica, V. (1969). Si Dios no me escuchara... IEA, 1, 121 127.

-- (1976). Árbol de mi sombra. Málaga: El Guadalhorce.

-- (1978). La religiosidad de Miguel Hernández y su poesía. Litoral, 73/75, 105-122.

-- (1981). Libro de las tribulaciones. Alicante: Publicaciones de la Obra Social y Cultural de la Caja de Ahorros Provincial de Alicante.

-- (1982). Un nuevo nombre en la poesía alicantina. En Alonso (1982), . 9-10.

-- (1985). El sembrador de vientos. Alicante: Caja de Ahorros Provincial.

-- (1986). La poesía del P. Ángel Barquilla Ramiro. En Barquilla, 11-15.

-- (1987). Espejo de la consumación. Valencia: Anteo.

-- (1990). Obra poética 1958-1988. Alicante: Caja de Ahorros del Mediterráneo.

- Molina, M. (1973). Antología de la Poesía alicantina actual (1940-1972). Alicante: Publicaciones de la Obra Social y Cultural de la Caja de Ahorros Provincial de Alicante.

-- (1989). Recuerdos del ambiente literario. Canelobre, 14/15, 39-45.

- Moreno Sáez, F. (ed.). (1994). La prensa en la provincia de Alicante durante la Guerra Civil (1936-1939). Alicante: Instituto de Cultura Juan Gil-Albert.

- Ors Montenegro, M. (2008). Elche, una ciudad en guerra (1936-1939). Elche: Librería Ali i Truc.

- Parra Pozuelo, M. (2008). El primer poema de Vicente Mojica y otras apariciones en su obra del tema de la ciudad bombardeada. AUCA, 14, 70-72.

Pérez Oca, M. Á. (2005). 25 de mayo: la tragedia olvidada. Alicante: Editorial Club Universitario.

Porpetta, A. (1981). Prólogo para el Libro de las Tribulaciones de Vicente Mojica. En Mojica, 11-17.

Prieto de Paula, Á. L. (1991). La diáspora de los Hijos de la ira (lírica española de 1944 a 1952). La lira de Arión. Alicante: Universidad de Alicante, 109-157.

Ramos, V. (1966). Literatura Alicantina (1839-1939) (Ensayo crítico y bio-bibliográfico). Madrid-Barcelona: Alfaguara.

-- (1979). Estudios de Literatura Alicantina (Primera Serie). Alicante: Publicaciones de la Obra Social y Cultural de la Caja de Ahorros Provincial de Alicante.

-- (1980). Hacia un concepto de literatura alicantina. Anales de Literatura Hispanoamericana, 9, 323-332.

-- (1990). Prólogo. En Mojica, 11-41.

-- (1992-1994). Alicante, en el Franquismo (Historia y Memoria). Alicante: Gráficas Vidal-Leuka, II Vol.

-- (1999). Cordialidad general. Diario Información, 8 de mayo, 21.

- Rubio, F. (1973). La poesía española en el marco cultural de los primeros años de posguerra. Cuadernos Hispanoamericanos, 276, 441-467.

- Rubio, F., y Falcó, J. L. (1981). Poesía española contemporánea. Historia y antología (1939-1980). Madrid: Alhambra.

- Ruiz Galiano, F. (2008). Vicente Mojica, en el recuerdo...”. AUCA, 14, 13-16.

- Solé, J. M., y Villarroya, J. (2003). España en llamas, la 


\section{Cultura de las Cuidados}

Guerra Civil desde el Aire. Madrid: Temas de Hoy.

- Valero Gómez, M. (2010). Nociones de filosofía poética en Antonio Machado. Esencialidad temporal y el NoSer”. AUCA. Revista Literaria y Artística, 20, 30-34.

-- (2011). Poesía de resistencia: una poética trágica y existencialista (Notas sobre Francisco Alonso Ruiz). AUCA, 23, 12-17.

-- (2012). Cuaderno de ahora mismo: hacia la última poesía de Francisco Alonso Ruiz. AUCA, 25, 8-9.

-- (2013). El tiempo de los héroes. Cuatro poetas alicantinos. Alicante: Aguaclara.
-- (2015). La Trastienda, un mito de la bohemia provinciana. El Taladro. Elche, la re-vista, 2 de febrero, 2015. Recuperado de http:www.eltaladro.es/2015/02/la-trastiendaun-mito-de-la-bohemia-provinciana/.

- Wahnón, S. (1987). Estética y crítica literarias en España (1940-1950). Tesis doctoral dirigida por el Dr. D. Antonio Sánchez Trigueros. Granada: Departamento de Lingüística general y Teoría de la Literatura, Facultad Filosofía y Letras.

- Zapata Pérez, A. (2012). Madurez y dignidad de un escritor. AUCA, 26, 43-44.

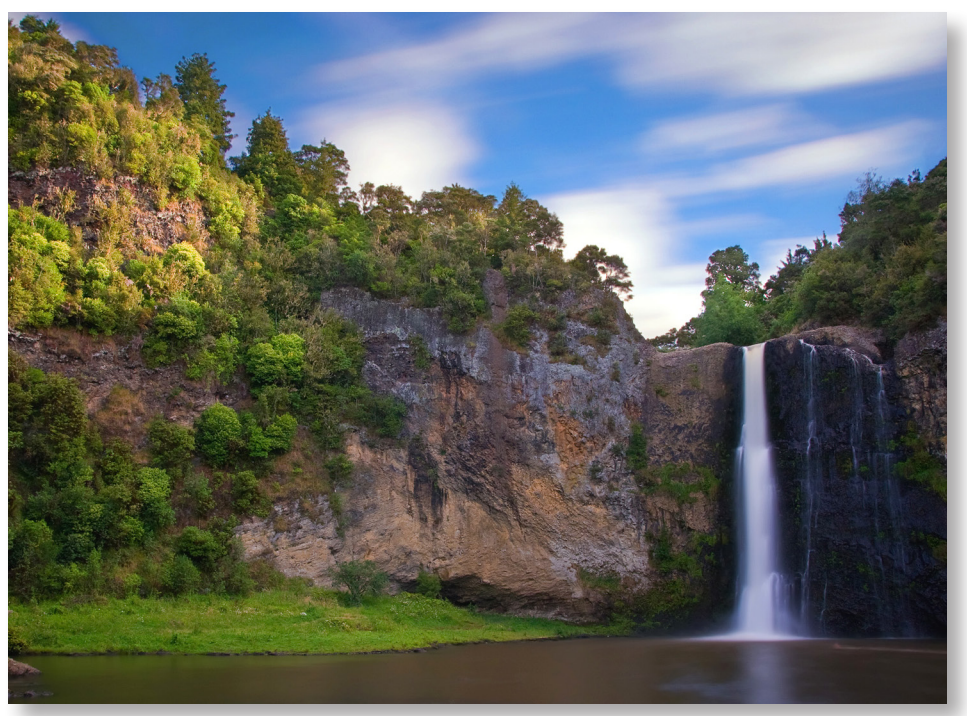

